\title{
A Study of Population based Diabetes Registry in Developed Countries
}

\author{
Seyyed Mohammad Tabatabaei ${ }^{1}$, Farkhondeh Asadi ${ }^{2}$, Hamid Moghaddasi ${ }^{2}$, Seyyed Raouf Khayami ${ }^{3}$ and \\ Mahtab Niroomand ${ }^{4}$
}

${ }^{1}$ PhD Student, Health information Management and Medical Informatics Department, Faculty of Paramedical Science, Shahid Beheshti University of Medical Sciences, Iran

${ }^{2}$ Health information Technology and Management Department, Faculty of Paramedical Science, Shahid Beheshti University of Medical Sciences, Iran ${ }^{3}$ Department of Computer Engineering and Information Technology, Shiraz University of Technology, Iran

${ }^{4}$ Division of Endocrinology, Department of Internal Medicine, Shahid Beheshti University of Medical Sciences, Iran

Submission: May 31, 2018; Published: June 07, 2018

*Corresponding author: Hamid Moghaddasi, Associate Professor in Health information Management and Medical Informatics, Health Information Technology and Management Department, School of Allied Medical Sciences, Shahid Beheshti University of Medical Sciences, Darband Street, Ghods Square (Tajrish), Tehran, Iran, Tel: +982122747373; Email: moghaddasi@sbmu.ac.ir

\section{Abstract}

Background and Purpose: Diabetes mellitus is the most common metabolic dysfunction, which can cause serious complications when it is not well-controlled. Thus, the population-based diabetes registry results in controlling and preventing diabetes by providing continuous care of patients, establishing connection among care providers, and monitoring and maintaining the quality of care. Some developed countries such as the United States, England, Denmark, Sweden, Italy and Australia are considered as the pioneers in this regard. The present study aimed to evaluate the components and characteristics of this registry, which can be informative for the developing countries.

Method: In the present review article, the papers published between 2000 and 2017 were reviewed. In order to access to the related scientific documentation, electronic search was conducted by using keywords such as diabetes registry, population-based registry and design of registry in the PubMed, Science Direct, InterScience, ProQuest and Google Scholar databases. The materials of all the studies papers were carefully analyzed and arranged in an appropriate sequence after extracting, categorizing, and integrating the material.

Literature Review: The population-based diabetes registry has attracted more attention in the developed countries due to the widespread prevalence of diabetes and the need for controlling. Thus, it is essential for developing countries to use these experiences. In the present study, population-based diabetes registry was reviewed in countries of the USA, Australia, England, Denmark, and Sweden.

Findings: Population-based diabetes registry is considered as a basic step for collecting, analyzing and distributing diabetes data and their complications. The study of the population-based diabetes registry in different countries such as the United States, England, Italy, Denmark, Australia and Sweden suggests that these countries include developed population-based diabetes registry based onthe structure of their health system. The findings indicated that registry goals, sources, elements, recorders, and the quality control of the data, as well as follow-up methods are the main components of a population-based diabetes registry in these developed countries.

Conclusion: Developing countries should implement the experiences of developed countries and try to develop a population-based diabetes registry as an important national program by considering this registry in these countries, as well as their own health system.

Keywords: Diabetes; Disease Registry; Population-based Diabetes Registry; Disease Registry System

Abbreviations: NDSS: National Diabetes Service Scheme; APEG: Australasian Pediatric Childhood Groups; NDA: National Diabetes Audit; DCS: Diabetes Centers; EMR: Electronic Medical Records; MDS: Minimum Data Set

\section{Introduction}

Diabetes mellitus has been emphasized for global health system for many reasons such as prevalence, complications, mortality, and huge cost [1,2]. Some studies indicated that diabetics can develop diabetic complications such as neuropathy and heart attacks in spite of an almost normal life. In addition, diabetes is considered as the most important cause of chronic renal failure and blindness among adults [3]. More than 7 million people get diabetes around the world every year, and it is regarded as the main cause of more than 3.8 million deaths. In fact, diabetes kills one person every 10 seconds $[4,5]$. Further, a large body of research indicated that actions are needed by means of diagnosing, preventing, and monitoring the diabetes accurately in 
order to prevent or delay the acute and chronic complications [59]. Further, the availability of adequate and accurate information about the patients, the nature of the disease, and time and location is regarded as an important factor in developing and implementing effective strategies for preventing and controlling a disease. To this end, establishing an information system is essential [7-9], which requires the implementation of a disease registry, as one of the secondary ways to prevent diabetes $[9,10]$. In the registry, the disease cases should be found first and their information should be collected, stored and abstracted accordingly. In the next stage, the reports are prepared and patients are followed-up [11].

In terms of size and spread, diabetes registry is divided into hospital-based and population-based category. Hospital-based diabetes registry is related to a hospital or health care facility while a population-based diabetes registry is concerned with a region or province or even the entire country [12-14]. Although a hospital-based registry cannot be a substitute for a populationbased diabetes registry, it can provide an opportunity to start the documentation process and provide information for the epidemiology of diabetes. Eventually, hospital-based diabetes registry is considered as the first step in creating a populationbased diabetes registry [14,15]. Population-based registries include all new cases of disease in a defined population (often a defined area such as a state) with an emphasis on epidemiology and public health [11]. This type of registry aimed to provide the statistics on the incidence of diabetes in a population, evaluation and control of diabetes, patient care improvement programs and community-based researches $[12,13]$. Despite the financial burden and resource constraints, population-based diabetes registry is considered to be the most valuable type of registry [13]. It is worth noting that population-based diabetes registry has priority over hospital-based diabetes registry in terms of importance and efficiency. Thus, like developed countries, implementing the population-based registry should be highlighted [14,15]. Given that the population-based diabetes registry includes data on the total number of diabetics in a community, it provides complete, appropriate and accurate information for community-based health management. In fact, population-based diabetes registry has priority over hospital-based diabetes registry because it considers a comprehensive approach and observes the state of diabetes in the entire population [16,17]. Considering the importance of population-based diabetes registry in managing the diabetes, reducing the cost, and improving planning and policy, the present study aimed to evaluate the status of population-based diabetes registry in developed countries. To this aim, The United States, England, Denmark, Sweden and Australia were considered.

\section{Method}

In order to conduct the present review article, the articles published between 2000 and 2017 were studied. In order to access to the related scientific documentation, electronic search was conducted by using keywords such as diabetes registry, population-based registry and design of registry at the PubMed,
Science Direct, InterScience, ProQuest and Google Scholar databases. Based on these keywords, 85 articles were found and35 papers were considered to cover the objectives of this study after the preliminary study. The criteria for entering the reviewed articles include its relation to registry, publishing between 20012017, publication in English, and (4) the availability of the full text of the articles. In addition, those papers which were not translated into English, presented at conferences, had only their abstracts available, and published only on websites were excluded. In order to evaluate the quality of the collected articles, the researchers reviewed the articles in terms of title, abstract, introduction, method, results, discussion, and references.

\section{Literature Review}

The population-based diabetes registry has attracted more attention in the developed countries due to the widespread prevalence of diabetes and the need for controlling. Thus, it is essential for developing countries to use these experiences. In the present study, population-based diabetes registry was reviewed in countries of the USA, Australia, England, Denmark, and Sweden. Diabetes Collaborative Registry is the first and the most important centralized registry for tracking and improving the quality of care, and providing metabolic care in the field of special and primary care for American diabetic patients [18-20]. This registry is an interdisciplinary effort led by the American College of Cardiology in partnership with the American Diabetes Association, the American College of Physicians, the American Association of Clinical Endocrinologists and the Joslin Diabetes Center [21,22]. The registry obtains data through primary care physicians, endocrinologists, cardiologists and other diabetes care providers [23-25]. In Australia, the National Diabetes Registry (NDR) has been introduced since 1987 by the Government, and was designed and implemented in 1999. This registry includes the information related to all diabetic and under treatment patients residing in Australia since 1999. The main data sources of NDR include the National Diabetes Service Scheme (NDSS) database as the first source, and Regional and Provincial data sources of Australasian Pediatric Childhood Groups (APEG) as the second one for diabetic children under the age of 14 [26,27].

In Europe, the representatives of the health departments and those patients related to different organizations from all European countries held a two-day meeting with the endocrinologists from WHO Regional Offices and the International Diabetes Federation (IDF) in San Antonio, Italy, in 1989. In this meeting, diabetes was determined as a major and growing health problem and emphasized that European countries should facilitate the identification process of diabetes and the use of resources to reduce this disease [28]. The structure of National Diabetes Service of England was published in December 2001, in which a set of standards were developed to improve follow-up, diagnosis, and treatment of diabetic patients [29,30]. National Diabetes Audit (NDA) registry collect the related data about diabetes care from general practitioners and hospitals, which help the NHS 
to improve the quality of care. The information of this center is secured through strict rules of confidentiality [31,32]. National Diabetes Register (NDR) is the national registry for diabetes in Sweden which is launched in 1996 by research teams including a group of physicians, medical staff and patients. This registry was initially designed only for type 1 diabetic patients, but it has become possible to include the patients with type 2 diabetes since 2000 [23]. In this regard, $100 \%$ of health professionals and 95\%of health care organizations participated in this program, among which $90 \%$ of diabetic patients were enrolled in this registry. By 2013, the number of registered patients was 325,000, among whom $88 \%$ were adult patients [33].

In 2006, Benedetti conducted a study entitled "The Umbria diabetes register in Italy" in order to provide a sample for national diabetes registry. Primary data sources in the registry are based on General Practitioners (GPS), Diabetes Centers (DCS) of Umbria, integrated with Electronic Medical Records (EMR). The study of population-based diabetes registry in various countries including The United States, England, Italy, Denmark, Australia, and Sweden suggests that these countries have designed registries based on the structure of their own health care system, leading to some similarities and dissimilarities $[20,26,27]$. The path of data flow and information feedback of the national diabetes registries are different in most of the developed countries around the world, but accordingly all data start from data sources and end with the national diabetes registry.

Preparing diabetes control and prevention programs comprehensively, improving the quality of care, conducting epidemiologic studies and reducing socioeconomic costs related to diabetes, identifying risk factors, monitoring the incidence and prevalence of disease, and establishing a comprehensive guide to disease management are reported as the most important goals of the national diabetes registries in the world [21,29,34,35]. All investigated registries are physician-based and collect demographic data, health care data, disease status, treatments, severity of disability and information on patients' experience about the disease. Based on the study of data resources in these countries, hospitals, health care organizations, general practitioners, and specialists are the main sources of information for the population-based diabetes registry in most of the developed countries [13,17,29,32]. Minimum Data Set (MDS) is regarded as another feature of the registry which is used to monitor the incidence and prevalence of disease, compile the training programs, as well as evaluating high-risk areas. In fact, most of national advanced registries around the world collect both demographic and therapeutic data, allowing them to achieve these goals. In addition, the international classification and coding system of ICD-10 were used to classify diabetes and its complications $[4,17]$.

Thus, it is very important to implement a variety of data processing techniques to evaluate care patterns, assess clinical implications, and ensure the cost effectiveness of healthcare.
Reports from the studies in all countries were presented based on the needs related to physicians, other individuals, and organizations to conduct therapeutic analysis and guide and help health and socio-economic groups for making decision [12-17]. Data are updated every three months in the US and once a year in other countries. In these countries, the data are stored according to the rules of confidentiality and patients' informed consent $[21,27,28]$. It is worth noting that the registries in the United States and England provide tools which enable patients to communicate with other patients so they can use others' experiences. Further, it is possible for patients to see their own condition and course of disease at any time, which is not possible in other registries [19]. Continuous patient follow-up, as a systematic process for monitoring patients' health status for medical care throughout their life and obtaining their life expectancy and quality of survival is considered as one of the most important uses of the registry $[13,17,36]$. Follow-up periods is 3 months in the United States and a year in other countries, which is done through telephone calling, electronic communications, and sending reminders to the patients [21,27-29,33].

\section{Results}

Establishing population-based diabetes registries can be a considerable step toward collecting, analyzing, and distributing diabetes data and its complications [33-35]. Increasing the diagnostic ability, identifying at-risk groups, developing strategies to reduce human and economic costs of diseases, developing healthcare regulations, and evaluating prevention and control programs are regarded possible only by the availability of a national diabetes registry. This type of registry can be useful for improving patient care, providing feedback, and evaluating the provided services [36,37]. The main components of the population-based diabetes registries in the developed countries are considered as the registry data sources, data elements, the types of registry processes and reports, the criteria of information quality measures, follow-up methods, the confidentiality, and privacy practices. These registries often collect original demographic data, course of disease, disability, drug information, hospitalization, and the test results. However, they are different in goals, content, structure, data architecture, time, and resources [24-29]. Table 1 illustrates the major components of populationbased diabetes registry in the United States, England, and Australia. Regarding the study results of the national diabetes registries in the developed countries, the following should be considered for establishing an efficient national diabetes registry:

a. Main Objectives of Registry: Goals, as the key for evaluating any system, can pave the way for developing the system forward and enhancing its efficiency. Based on the conducted studies, the key goals in implementing a national diabetes registry consist of describing the course of the disease, evaluating therapeutic measures, improving the quality of care, monitoring the care, controlling the disease, and conducting the studies. 
Table 1: Major components of population-based diabetes registry in the United States, England, and Australia.

\begin{tabular}{|c|c|c|c|}
\hline Country/ Criterion & The United States & England & Australia \\
\hline Goals & $\begin{array}{l}\text { Identifying patients with diabetes } \\
\text { and continuing their care } \\
\text { Identifying and tracking patients } \\
\text { at risk of the complications } \\
\text { of diabetes and offering their } \\
\text { necessary therapeutic services } \\
\text { Assessing the prevention and } \\
\text { control of diabetes and giving the } \\
\text { necessary professional and general } \\
\text { instructions } \\
\text { Providing the statistics of } \\
\text { disease and mortality associated } \\
\text { with diabetes }\end{array}$ & $\begin{array}{c}\text { Establishing and evaluating } \\
\text { comprehensive diabetes diagnostic } \\
\text { and control programs } \\
\text { Giving correct notices to patients } \\
\text { and specialists } \\
\text { Providing health information } \\
\text { feedback to maintain health } \\
\text { Monitoring and controlling the } \\
\text { quality of care using information } \\
\text { technology systems } \\
\text { Applying effective methods } \\
\text { to prevent costly diabetes } \\
\text { complications }\end{array}$ & $\begin{array}{l}\text { Providing effective health care for } \\
\text { diabetic patients } \\
\text { The goals of St. Vincent (the goals } \\
\text { mentioned for England) } \\
\text { Epidemiology of diabetes and its } \\
\text { complications }\end{array}$ \\
\hline Type & Physician-oriented & Physician-oriented & Physician-oriented \\
\hline Executive officials & $\begin{array}{l}\text { American College of Cardiology } \\
\text { American Diabetes Association } \\
\text { College of American Physicians } \\
\text { American Endocrine Society } \\
\text { Joslin Diabetes Center }\end{array}$ & $\begin{array}{c}\text { The National Health Service (NHS) } \\
\text { of the United Kingdom }\end{array}$ & Australian Government \\
\hline Types of data & $\begin{array}{l}\text { The patient's demographic data } \\
\text { Clinical patient data } \\
\text { Medicinal data } \\
\text { Identification data of diabetes care } \\
\text { providers } \\
\text { Mortality data } \\
\text { Patient follow-up data }\end{array}$ & $\begin{array}{c}\text { Patient demographic data } \\
\text { Clinical patient data } \\
\text { Medicinal data } \\
\text { Identification data of diabetes care } \\
\text { providers } \\
\text { Mortality data } \\
\text { Patient follow-up data }\end{array}$ & $\begin{array}{c}\text { Patient demographic data } \\
\text { Clinical patient data } \\
\text { Medicinal data } \\
\text { Identification data of diabetes care } \\
\text { providers } \\
\text { Mortality data } \\
\text { Patient follow-up data }\end{array}$ \\
\hline Data sources & $\begin{array}{c}\text { General practitioners } \\
\text { Endocrine specialists } \\
\text { Cardiologists } \\
\text { Other Diabetes Service Providers }\end{array}$ & $\begin{array}{l}\text { Hospitals } \\
\text { General practitioners } \\
\text { Primary care centers } \\
\text { Information systems }\end{array}$ & $\begin{array}{l}\text { National Diabetes Service Scheme } \\
\text { (NDSS) Database } \\
\text { Australasian Pediatrics Endocrine } \\
\text { Group (APEG) }\end{array}$ \\
\hline Types of data processing & $\begin{array}{l}\text { Statistical analyses by using } \\
\text { several statistical methods such as } \\
\text { correlation coefficient (correlation } \\
\text { evaluation and the relationship } \\
\text { between registry variables) }\end{array}$ & $\begin{array}{l}\text { Processing information by using } \\
\text { descriptive statistics }\end{array}$ & $\begin{array}{l}\text { Using descriptive statistics such } \\
\text { as mean and logistic regression to } \\
\text { calculate odds ratio }\end{array}$ \\
\hline $\begin{array}{l}\text { Information Quality Control } \\
\text { Criteria }\end{array}$ & $\begin{array}{l}\text { Completeness } \\
\text { Information accuracy control } \\
\text { Accuracy in the interpretation of } \\
\text { disease information } \\
\text { Quality control at the center for } \\
\text { disease control } \\
\text { Controlling the final report } \\
\text { Information control by computer }\end{array}$ & $\begin{array}{l}\text { Completeness } \\
\text { Information accuracy control } \\
\text { Accuracy in the interpretation of } \\
\text { disease information } \\
\text { Controlling the final report } \\
\text { Information control by computer }\end{array}$ & $\begin{array}{c}\text { Completeness } \\
\text { Information accuracy control } \\
\text { Accuracy in the interpretation of } \\
\text { disease information } \\
\text { Information control by computer }\end{array}$ \\
\hline Information updating & Every 3 months & Annually & Annually \\
\hline Types of reports & $\begin{array}{l}\text { Publishing research reports in } \\
\text { scientific journals } \\
\text { Providing reports based on the } \\
\text { doctors' needs for therapeutic } \\
\text { analysis }\end{array}$ & $\begin{array}{c}\text { Providing reports based on the } \\
\text { doctors' needs for therapeutic } \\
\text { analysis }\end{array}$ & $\begin{array}{c}\text { Providing reports based on the } \\
\text { doctors' needs for therapeutic } \\
\text { analysis }\end{array}$ \\
\hline follow-up & $\begin{array}{l}\text { Connecting and tracking through } \\
\text { letters and phone numbers }\end{array}$ & $\begin{array}{l}\text { Connecting and tracking through } \\
\text { letters and phone numbers }\end{array}$ & $\begin{array}{l}\text { Connecting and tracking through } \\
\text { letters and phone numbers }\end{array}$ \\
\hline
\end{tabular}


b. Establishing an Evaluation and Monitoring Committee: Establishing a Diabetes Information Advisory Committee is essential for providing counseling, monitoring, implementation, and policy-making services at national level. The committee should include physicians and health information management experts, nutritionist, statisticians, epidemiologist, and information technology experts.

c. Determining the Type of Data and Data Sources: Occurrence data and data collection method are regarded as two important registry components. The data items collected in this system should be designed in such a way that they should be specific to a given time period. Most importantly, registries require a specific managerial structure and a regular program can play an effective role in its creation. Then, the process of selecting the data elements starts after determining the domain of the registry. Thus, the data elements of the registries are different based on their goals. The dataset used in most registries includes a demographic data set (first name, last name, sex, race, birth date, place of birth, national code, insurance code, marital status, occupation, and education), recorded contact information for registry in order to contact directly with the registrar, recorded contact information of another person for tracking and responding (address, telephone, email), source of information (service provider information, hospital name, laboratory name, telephone number, address, contact information), accommodation information at the time of registration (country, province, city, district/village, and postal code), medical history data (diseases and conditions of the patient, the onset and duration of the illness, the history of treatment and medications, diagnostic tests and their outcomes, actions, consequences, referrals to the emergency department, visits to the hospital including the length of stay, and follow-up data sets such as safety (side effect report), performing diagnostic tests and their results, progression of disease severity, therapeutic measures and outcomes, death, cause and date of death, and tracking other datasets such as the changes in medical status, living conditions, drug, treatment and insurance coverage. Data sources include laboratories, offices, hospitals, health care organizations, and local registry offices. In addition, the ICD-10 code is used to record the disease and its complications.

d. Information Quality Control Measures: The quality information is the result of the quality of data which is determined by the completeness of the coverage, the estimated approximation of the disease incidence per year in a specific population, comparing the data collected each year with the last year in the same region, completeness of details, quick review of the collected information, random examination of some information, frequent information control, information accuracy control, accuracy in the interpretation of disease information, quality control at the center of disease control, control of the final report before each analysis and printing, and the information control by computer by using standards and quality control indicators.

e. Follow-Up Methods for Diabetic Patients: Patient identifiers can be easily used to identify and follow up patients. These IDs play a role in identifying the patients who cannot be tracked due to death (e.g. through the National Death Index). In addition children's field studies become feasible by linking up with birth certificates. Further, patient identifiers are considered as a standard for analyzing and eliminating repetitive patients. Follow-up courses are usually regulated at one-year intervals and reminder letters can be prepared and sent to the patients by using the registry.

\section{Discussion and Conclusion}

The lack of a national diabetes registry and the inadequacy of this system in hospitals and health centers of the country are confirmed by the gaps in identifying diabetic patients, at-risk groups, geographical dispersion, demographic characteristics, economic, social and human impacts, guidance, decision-making and planning, statistics and information organizations [37,38]. Using the experience of developed countries in this area can pave the way for designing the national registry of diabetes in the country in such context $[39,40]$. In fact, the registry of diabetes is a secondary solution for managing diabetes which can be effective in studying and evaluating the interaction of diabetes with other diseases, as well as improving the quality of care and follow-up among the patients continuously. In general, the study of population-based diabetes registry in developed countries has shown that this kind of registry is a useful tool in managing diabetes, and the resulting information sources are highly valuable and can provide accurate information on the outbreak of the disease, risk factors and effective treatment plans in a community, and enable epidemiological studies. Therefore, according to their health system, developing countries should focus on establishing a population-based diabetes registry as a national program and use its benefits and capabilities. Further, designing and implementing such a registry is subject to the provision of equipment, location and the appointment of population-based diabetes registry executives. Finally, it is necessary to define a theoretical framework which is possible by using the lessons from developed countries in this field and applying their successful experiences about registries in order to develop a successful national diabetes registry, establish, and preventing potential problems [41].

\section{References}

1. Salehmoghaddam AR, Khosravi A, Karimi H, Gholami H (2013) An investigation of The Effect of E-learning Education Method on Dietary Regimen in Type 2 Diabetic Patients. Evidence Based Care Journal 3(3): 51-58.

2. Hamadzadeh S, Ezate G (2014) A determination of self-care performance among diabetic patients in endocrine clinic of Taleghane hospital in Tehran. IJNR 8 (4): 11-18.

3. Alavinia SM et al. (2012) Diabetics type 2 control and prevention plan. Sepidbarg Publisher. 
4. Hosseini A, Moghaddasi H, Jahanbakhsh M (2010) Designing Minimum Data sets of Diabetes Mellitus: Basis of Effectiveness Indicators of Diabetes Management. Health Information Management 7(3): 340.

5. Comprehensive diabetes control and prevention program (2017) Ministry of Health and Medical Education. Deputy of Health.

6. Moghaddasi H, Abolhassani M, Kazemi A (2016) Presenting an ObjectOriented Functional Model for Diabetes Registry Software. Journal of Health and Biomedical Informatics 3(3): 186-194.

7. Molaei S, Hosseini M, Tabatabaee SM, Tafreshi MZ (2017) Designing, Producing and Evaluating of Educational Multi-Media Application for the Self-Care of Patients with Type 2 Diabetes. Indo American Journal Of Pharmaceutical Sciences 4(5): 1313-1318.

8. Nanan DJ, White F (1997) Capture-Recapture: Reconnaissance of a Demographic Technique in Epidemiology. Chronic Dis Can 18(4): 144148.

9. Abdelhak, Mervat (2001) Health Information Management of a strategic Resource Philadel: W.B. Saunders.

10. Larsson S, Lawyer P, Garellick G, Lindahl B, Lundström M (2012) Use of 13 disease registries in 5 countries demonstrates the potential to use outcome data to improve health care's value. Health Affairs 31(1):220227.

11. (1999) National Cancer Institute(NCI) (3 $3^{\text {rd }}$ edn.), SEER Program Self Instructional Manual for Cancer Registrar.

12. Navarro C, Martos C, Ardanaz E, Galceran J, Izarzugaza I, et al. (2010) Population-based cancer registries in Spain and their role in cancer control. Annals of Oncology 21(suppl 3): iii3-iii13.

13. Rankin J, Best K (2014) Disease registers in England. Paediatrics and Child Health 24(8): 337-342.

14. Hedgecoth J (2010) Prevention and Chronic Care Advisory Council, p. 1-7.

15. Valsecchi MG, Steliarova Foucher E (2008) Cancer registration in developing countries: luxury or necessity?. Lancet Oncol 9(2): 159167

16. (2017) Orphanet Report Series-Rare Disease Registries in Europe.

17. Gliklich RE, Levy D, Karl J, Leavy M, Taylor Th, et al. (2012) Registry of Patient Registries (RoPR): Project Overview. Research from the Developing Evidence to Inform Decisions about Effectiveness (DEcIDE) Network.

18. Suzanne V Arnold, Silvio E Inzucchi, Fengming Tang, Darren K McGuire, Sanjeev N Mehta, et al. (2017) Using the Diabetes Collaborative Registry (DCR) to Estimate the Potential Real-world Impact of the Iris Trial on Improving Outcomes in Patients With Cerebrovascular Disease. Cardiovascular Quality and Outcomes 10: A013.

19. The Diabetes Collaborative Registry Homepage.

20. Diabetes Collaborative Registry releases baseline, quality of care data American Association for the Advancement of Science Homepage.

21. (2017) American College of Cardiology. Diabetes Collaborative Registry: A Powerful Collaboration to Transform the Future of Diabetes Care.

22. American College of Cardiology (2010) NCDR® PINNACLE Registry® v1.3 Full Data Dictionary.
23. Suzanne V, Goyal A, Inzucchi SE, McGuire DK, Tang F, et al. (2017) Quality of Care of the Initial Patient Cohort of the Diabetes Collaborative Registry®. JAm Heart Assoc 6(8): e005999.

24. Arnold SV, Silvio E Inzucchi, Darren K McGuire, Sanjeev N Mehta, Abhinav Goyal, et al. (2016) Evaluating the Quality of Comprehensive Cardiometabolic Care for Patients with Type 2 Diabetes in the U.S.: The Diabetes Collaborative Registry. Diabetes Care. 39(7): e99-e101.

25. (2015) American College of Cardiology. Diabetes Collaborative Registry $^{\mathrm{TM}}$ v1.2 Data Collection Form.

26. (2004) Diabetes Australia Guideline Development Consortium. National evidence based guidelines for management of type 2 diabetes mellitus.

27. Eliasson B, Cederholm J, Nilsson P, Gudbjörnsdóttir S, Steering Committee of the Swedish National Diabetes Register (2005) The gap between guidelines and reality: type 2 diabetes in a national diabetes register 1996-2003. Diabet Med 22(10): 1420-1426.

28. Colagiuri R, Short R, Buckley A (2010) The status of national diabetes programmes: a global survey of IDF member associations. diabetes research and clinical practice 87(2): 137-142.

29. Newton J, Garner S (2002) Disease Registers in England: A Report Commissioned by the Department of Health Policy Research Programme in Support of the White Paper Entitled Saving Lives: Our Healthier Nation. Institute of Health Sciences University of Oxford.

30. https://www.diabetes.org.uk.

31. (2017) NHS. National Diabetes Audit: how your information is used to help improve diabetes care.

32. (2017) Diabetes UK. State of the Nation 2016: Time to take control of diabetes.

33. Elfgren I, Grodzinsky E, Törnvall E (2016) The Swedish National Diabetes Register in clinical practice and evaluation in primary health care. Prim Health Care Res Dev 17(6): 549-558.

34. Gudbjörnsdottir S, Cederholm J, Nilsson PM, Eliasson B (2003) The national diabetes register in Sweden. Diabetes care 26(4): 1270-1276.

35. Cherubini V, Carle F, Gesuita R, Iannilli A, Tuomilehto J, et al. (1999) Large incidence variation of type I diabetes in central-southern Italy 1990-1995: lower risk in rural areas. Diabetologia, 42(7): 789-792.

36. Parkin DM (2008) The role of cancer registeries in cancer control. The Japan Society of Clinical Oncology 13(2): 102-11.

37. Robertson K, Crawford E, Fisher M, Knox C, Lamont A, et al. (2003) Scottish Diabetes Care Dataset. SCIDC Steering Group.

38. Moghaddasi H, Ayani S, Valizadeh M, Rahimi F (2017) Insulin Therapy Decision Support System: A Study of its Evolutionary Path. J Health Inform Manag 1:1.

39. Disease Registry Program (2015) Ministry of Health and Medical Education. Deputy of Research and Technology.

40. Delavari A, Mahdavi A, Norouzi A, Yarahmadi Sh (2005) Nurse and Diabetes. Sadra Publication, Ministry of Health and Medical Education, Deputy of Health.

41. (2012) Executive Guideline for Special Care in comprehensive program of controlling and preventing diabetes. Ministry of Health and MedicalEducation. Deputy of Treatment. 
(c) (P) This work is licensed under Creative

DOI: 10.19080/JOJNHC.2018.08.555732

\section{Your next submission with Juniper Publishers} will reach you the below assets

- Quality Editorial service

- Swift Peer Review

- Reprints availability

- E-prints Service

- Manuscript Podcast for convenient understanding

- Global attainment for your research

- Manuscript accessibility in different formats

( Pdf, E-pub, Full Text, Audio)

- Unceasing customer service

Track the below URL for one-step submission https://juniperpublishers.com/online-submission.php 